\title{
Physical medicine after limb transplantation. Therapeutic effects of physical procedures in the treatment of limb transplantation after cut-off by a threshing machine - Case report
}

\author{
Jarosław Pasek ${ }^{1, A-F}$, Tomasz Pasek ${ }^{2, A-F}$, Grzegorz Cieślar, ${ }^{3, A-F}$, Aleksander Sierońn ${ }^{3, A-F}$ \\ ${ }^{1}$ Academy of Jan Długosz, Institute of Physical Education Tourism and Physiotherapy, Częstochowa, Poland \\ ${ }^{2}$ Rehabilitation Unit, St. Barbara Provincial Specialist Hospital No. 5, Poland \\ ${ }^{3}$ Chair and Department of Internal Diseases, Angiology and Physical Medicine, Medical University of Silesia in Katowice, \\ Poland \\ A - Research concept and design; B - Collection and / or assembly of data; C - Data analysis and interpretation; \\ $D$ - Writing the article; $E$ - Critical revision of the article; $F$ - Final approval of article
}

Pasek J, Pasek T, Cieślar G, Sieron A. Physical medicine after limb transplantation. Therapeutic effects of physical procedures in the treatment of limb transplantation after cut-off by a threshing machine - Case report. Ann Agric Environ Med. 2018; 25(2): 241-243. doi: 10.26444/aaem/75112

\section{Abstract}

Introduction. The number of accidents in agriculture involving children as the victims continues to increase year-by-year. Parents often allow children to perform certain tasks, or even entrust them to perform such tasks as a duty.

Case report. The paper presents results of treatment using a 3D magnetic field in a 31-year- old patient after transplantation of the upper extremity of the arm. Amputation of the extremity had been caused by an accident (hand cut-off by a threshing machine). The therapeutic cycle for the patient constituted of 3 series of 15 daily procedures, performed for 15 minutes. There was a break of 4 weeks between sessions. Additionally, the patient performed kinesitherapy exercises in the outpatient clinic.

Conclusions. The results obtained regarding improvement of the functional condition of the limb showed that in the complex planning of treatment, the taking into account of the physical medicine procedures should be indispensable.

I Key words

limb transplantation, physical medicine, accident at field

\section{INTRODUCTION}

In rural areas in particular, the farm is the home for children, their playground and a place of work (particularly during holidays). This brings about the risk of serious threats related to the use of tractors, circular or chain saws, as well as other agricultural machinery, and trailers. Despite the fact that the percentage of children (under 15 years of age) who are the victims of accidents is not so substantial (only $2-3 \%$ of all victims of accidents in agriculture), the implications and consequences of those accidents, including fatal accidents, may be enormous $[1,2]$.

Year-by-year, the number of patients who require tissue reconstruction in connection with mechanical traumas suffered (traffic accidents), oncologic surgical procedures, or congenital defects increases [3]. As is known, the upper limbs are extremely important for humans, due to the various functions they perform. Upper limb traumas may affect only the soft tissues, or may be much more serious, and may lead to fractures of hand bones, crushing by heavy objects falling on them, as well as crushing caused by the pulling of the extremity into farming equipment $[4,5]$.

The basic factor determining the results of a transplantation is the degree of genetic compatibility of the donor and recipient. It happens that the surgical procedure with

Address for correspondence: Jarosław Pasek, Academy of Jan Długosz in Częstochowa, Institute of Physical Education Tourism and Physiotherapy, Poland, Poland

e-mail: jarus_tomus@o2.pl

Received: 19.05.2017; accepted: 19.06.2017; first published: 15.07.2017 subsequent motor rehabilitation often fail to produce the assumed therapeutic effect. The transplanted limb allows for visual assessment immediately after the procedure, while the period in which sensory and motor functions are restored is significantly extended in time. In the case of transplantations of upper limbs, the monitoring of possible development of transplant rejection is based mainly upon visual assessment (principally of typical changes concerning the skin) $[3,6,7]$.

\section{OBJECTIVES}

The aim of the study is to present the beneficial results of treatment with the application of a 3D magnetic field in a 31-year-old patient after the procedure of upper limb transplantation performed at arm level after an accident in a field.

\section{CASE REPORT}

Patient MB, aged 31, came to the Clinic of Internal Diseases, Angiology and Physical Medicine, due to not fully satisfactory results of treatment after transplantation of the upper limb at arm level (2012). Amputation of the limb was performed due to the fact that the limb had been cut-off by a threshing machine (1981)

The physical examination performed on admission revealed: decreased muscle power in the area of right humeral joint (score 3 in Lovett's scale), movement (supination and 


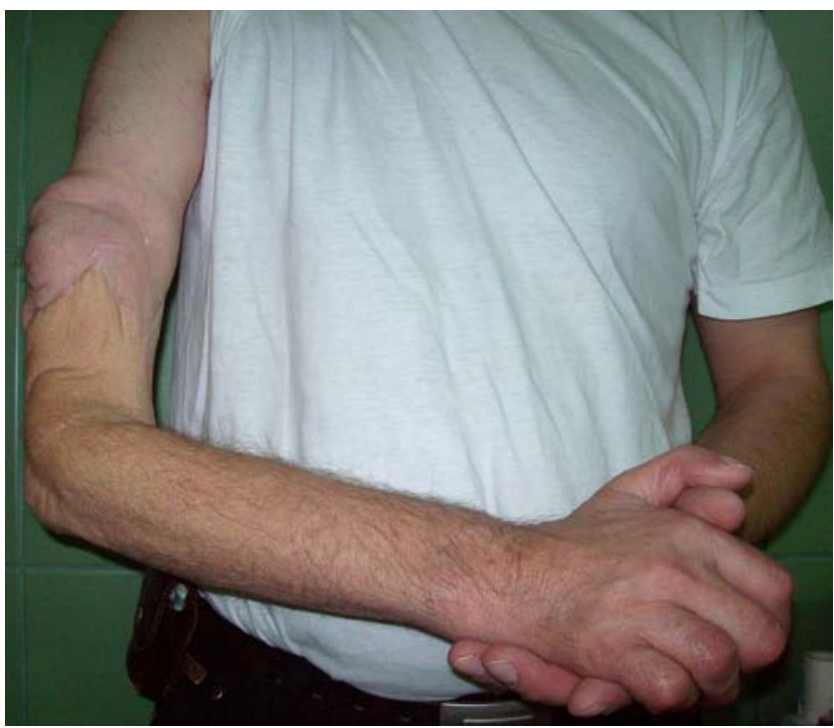

Figure 1. The local state after limb transplantation after cut off threshing machine

pronation) of the forearm in elbow joint, as well as impossiblity to perform movement of the palm and compulsory position of the limb, which manifested in its relaxation with superficial sensibility maintained.

Table 1. Evaluation of range mobility in elbow joint (before and after the end of therapy) in patient after limb transplantation

\begin{tabular}{lcc}
\hline & Before therapy & After therapy \\
\hline 1. Flexion movement in elbow joint & $120^{\circ}$ & $145^{\circ}$ \\
\hline 2. Extension movement in elbow joint & $20^{\circ}$ & $25^{\circ}$ \\
\hline 3. Supination movement of the forearm & $0^{\circ}$ & $90^{\circ}$ \\
\hline 4. Pronation movement of the forearm & $5^{\circ}$ & $90^{\circ}$ \\
\hline
\end{tabular}

Additionally, EMG examination was performed, which revealed: "In the right median, ulnar, and radial nerve no sensory conduction response was registered at very high stimulus threshold. In the right radial nerve there is no movement conduction response".

Physical treatment. 3D magnetic field procedures, with the use of SHARC Inside device (Fig. 2) were initiated for

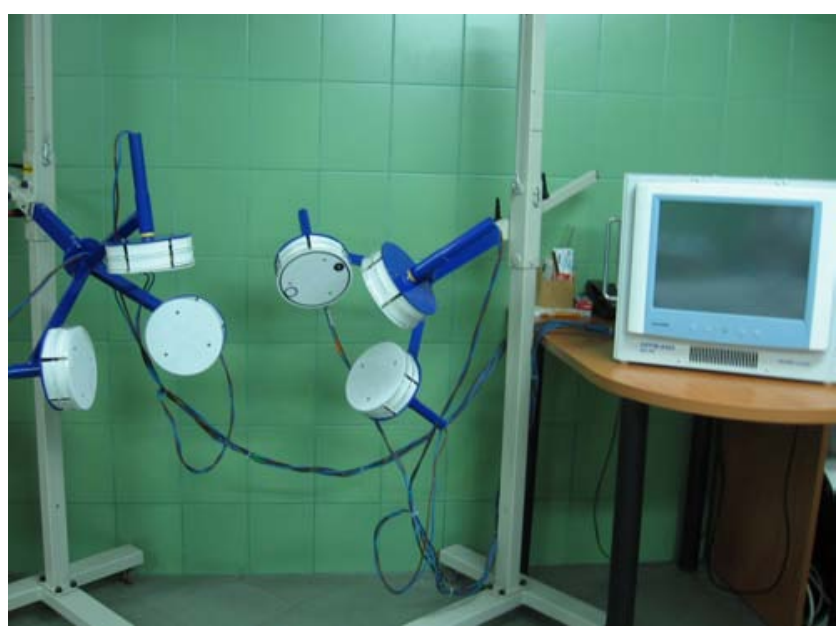

Figure 2. The apparatus SHARC Inside to application of spatial magnetic fields, Poland the patient [8]. An example of such solutions is the device for providing therapy using a spatial magnetic field. The magnetic field is generated in the system of 3 pairs of spatially-oriented field applicators, coupled with each other (so-called magnetic coils), whose planes are arranged at $90^{\circ}$ to one to another [9].

The procedures were performed twice a day, with the following physical parameters of the magnetic field: course of magnetic field impulse - procedure 1 - sinusoidal, procedure 2 - triangular), frequency $-40 \mathrm{~Hz}$, magnetic induction $30 \mathrm{mT}$ ). Time of the first and second procedure -15 minutes. At the same time, throughout the treatment, the patient underwent kinesitherapy exercises. The therapeutic cycle for the patient constituted of 3 series of 15 daily procedures, performed for 15 minutes, with intermissions on Saturdays and Sundays. There was a break of 4 weeks between sessions. The procedures were performed with the patient in sitting position.

\section{RESULTS}

After completion of the therapy (5 months), a gradual improvement of motor functions was observed in innervation of the area affected by the disease process in the elbow joint. Additionally, a slight improvement was obtained regarding muscle power in the area of the right humeral joint (score 4 in Lovett's scale). In the EMG follow-up the result was: "The examination revealed responses in muscle, having lowered amplitude. Slowed down sensomotor conduction. Medium level reduction of sensory potential in damaged nerves".

\section{DISCUSSION}

In the light of progress in transplantology, one can assume that transplantation of an upper limb may be the most rational method of treatment in that group of patients. However, the limb transplantation is not the end a long process of rehabilitation, it is only the beginning. The possibility of restoring limb functions after transplantation or replantation through physiotherapeutic procedures ranks among the biggest achievements of $20^{\text {th }}$ century traumatology [5]. Only complex treatment gives the possibility of restoring optimal functions of damaged nerves [10].

As results from numerous clinical studies have shown, the grounds for the therapeutic influence of magnetic fields, in case of lesions of peripheral nerves, are - first of all stimulation of separation and regeneration processes in the nervous tissue $[8,10]$, improved perfusion of the nerve [11], and improvement of nervous tissue metabolism $[8,11]$. The modification of stimuli conduction speed in nerve fibres is also enhanced $[8,9]$. Enhanced treatment efficiency is achieved thanks to kinesitherapy conducted under the conditions of magnetic field influence $[11,12]$.

\section{CONCLUSIONS}

The application of a 3D magnetic field to the patient after upper limb transplantation resulted in improved conductivity in lesions of peripheral nerves. 


\section{REFERENCES}

1. Spinner RJ, Amadio PC. Compressive neuropathies of the upper extremity. Clin Plast Surg. 2003; 2: 155-173.

2. Anavian J, Gauger EM, Schroder LK, Wijdicks CA, Cole PA. Surgical and functional outcomes after operative management of complex and displaced intra-articular glenoid fractures. J Bone Joint Surg Am. 2012; 94(7): 645-653.

3. Amadio P.C. What's new in hand surgery? J Bone Joint Surg Am. 2004; 2: 442-448.

4. Zhang S, Tong D, Li M. Side-to-side neuropathy for high-level peripheral nerve injuries. Acta Neurochir. 2012; 5: 120-127.

5. Tagliafico A, Altafini L, Garello I. Traumatic neuropathies: spectrum of imaging findings and postoperative assessment. Semin Musculoskelet Radiol 2010; 14: 512-522.

6. Dahlin LB. Techniques of peripheral nerve repair. Scand J Surg. 2008; 97: $310-316$
7. Han AM, Heo H, Kwon YK. Berberine Promotes Axonal Regeneration in Injured Nerves of the Peripheral Nervous System. J Med Food. 2012; 8: 17-23.

8. Swart E, Nellans K, Rosenwasser M. The Effects of Pain, Supination, and Grip Strength on Patient-rated Disability After Operatively Treated Distal Radius Fractures. J Hand Surg Am. 2012; 10: 17-25.

9. Sieroń A. et al. Aplication magnetic fields in medicine. $2^{\text {nd }}$ ed. Alfa Medica Press, Bielsko-Biała 2002.

10. Sieroń A, Pasek J, Biniszkiewicz T. Spatial magnetic fields - new form the therapy? Polish Balneology. 2007; 1: 8-10.

11. Hollister AM, Simoncini A, Sciuk A. High frequency ultrasound evaluation of traumatic peripheral nerve injuries. Neurol Res. 2012; 34: 98-103.

12. Galanakos SP, Zoubos AB, Johnson EO. Outcome models in peripheral nerve repair: Time for a reappraisal or for a novel? Microsurgery. 2012; 10: $20-27$. 